\title{
ÚLTIMAS TENDENCIAS EN LA UNIÓN EUROPEA SOBRE LAS ACCIONES COLECTIVAS DE CONSUMO. LA POSIBLE INTRODUCCIÓN DE FÓRMULAS DE ADR*
}

\author{
Ana MONTESINOS GARCÍA \\ PROFESORA CONTRATADA RAMÓN Y CAJAL \\ UNIVERSITAT DE VALÈNCIA
}

SUMARIO: I. Introducción. II. Las acciones colectivas en Europa. II.I. Panorama actual de las acciones colectivas en Europa. II. 2. Iniciativas europeas. III. Tutela judicial de las acciones colectivas. III.I. ¿Qué se entiende por acciones colectivas?. III.2. Legitimación de las partes y control judicial. III.3. Constitución de la parte demandante. III.4. Suministro de información. III.5. Financiación. III.6. Litigios transfronterizos. IV. Las ADR y las acciones colectivas. IV.r. Propuestas europeas. IV.2. Viabilidad o no del ejercicio de acciones colectivas a través a través de fórmulas transaccionales o del arbitraje. IV.2.I. Las transacciones colectivas. IV.2.2. El arbitraje colectivo. IV.3. Experiencias europeas. IV.3.I. El arbitraje colectivo de consumo español. IV.3.2. La transacción colectiva holandesa en materia de daños en masa.

RESUMEN: En el presente trabajo se abordan las últimas iniciativas en la Unión Europea en lo que a las acciones colectivas en materia de consumo se refiere. Se analizan las principales cuestiones procesales de este tipo de acciones desde una perspectiva judicial, tales como la legitimación, el control judicial, la constitución de la parte demandante, el suministro de información, la financiación y los litigios transfronterizos. Se presentan las recomendaciones y pautas que la Comisión Europea trata de configurar a modo de principios comunes, y se compara con el estado de la cuestión en nuestro país. Por último, se discute la posible introducción de fórmulas alternativas de resolución de conflictos (ADR) en las acciones colectivas, especialmente de fórmulas transacciones y del arbitraje. Para ello, se describen dos ejemplos pioneros en Europa: el arbitraje de consumo colectivo español y la transacción colectiva holandesa en materia de daños en masa.

PALABRAS CLAVE: acciones colectivas, Unión Europea, métodos alternativos de resolución de conflictos, arbitraje.

ABSTRACT: This article deals with the last initiatives in the European Union in consumer collective redress. It analyses the main procedural questions of this type of actions from a judicial perspective, such as: legal standing, judicial control, constitution of the claimant's party, provision of information, funding and cross-border cases. It presents the recommendations and guidelines that the European Commission tries to organize as common principles, and compares it with the situation in our country. Finally, it discusses the possibility of introducing alternative disputes resolution methods (ADR) in collective redress. For that, it describes two pioneer examples in Europe: the Spanish consumer collective arbitration and the Dutch collective settlement in mas damage cases.

KEYWORDS: Collective redress, European Union, Alternative Dispute Resolution, Arbitration, Arbitration.

\footnotetext{
* Estudio redactado en el marco del Proyecto DER 2013-44749-R (Ministerio de Economía y Competitividad).
} 


\section{Introducción}

La Unión Europea se ha propuesto como uno de sus objetivos primordiales mantener y desarrollar un espacio de libertad, seguridad y justicia, en el que además se garantice un nivel elevado de protección de los consumidores. Para garantizar que los ciudadanos puedan obtener una reparación efectiva por los daños que se hayan podido ocasionar en el ámbito del consumo y, en particular en los litigios transfronterizos, resulta imprescindible que se establezcan soluciones procesales acordes con el Derecho de la Unión Europea.

Hasta el momento, el Derecho procesal europeo ha tratado de responder a los litigios individuales de los consumidores a través de diferentes mecanismos de tutela, entre los que destacan: el proceso europeo de escasa cuantía ${ }^{\mathrm{r}}$, el proceso monitorio europeo ${ }^{2}$, el título ejecutivo europeo para créditos no impugnados ${ }^{3}$, la mediación ${ }^{4}$, la resolución alternativa de litigios en materia de consumos ${ }^{5}$ la resolución de litigios en línea en materia de consumo ${ }^{6}$, etc. Sin embargo, no todos estos instrumentos proporcionan soluciones eficaces cuando la infracción del Derecho de la Unión Europea perjudica a un grupo de ciudadanos, a los cuales, la interposición de acciones individuales puede no resultarles un mecanismo práctico para obtener las correspondientes indemnizaciones por daños y perjuicios o para poner fin a las prácticas ilegales (solicitar su cesación).

Debemos ser conscientes de que los mercados de consumo crecen cada vez más, a la vez que adquieren un carácter transfronterizo, por lo que un número elevado de consumidores puede verse perjudicado por la misma infracción, convirtiéndose cada uno de ellos en víctima de prácticas idénticas por parte de un mismo empresario, comerciante $u$ otro operador económico; estaremos entonces ante lo que viene denominándose «daños masivos».

En principio, estos consumidores tendrán la opción de recurrir individualmente a la Justicia para obtener una compensación de forma individual, pero la práctica ha demostrado que suelen ser reacios a emprender acciones particulares contra tales prácticas ilegales, principalmente cuando la pérdida individual es relativamente escasa en comparación con los costes a los que puede ascender el litigio ${ }^{7}$. Por tanto, si bien los daños

${ }^{\mathrm{r}}$ Reglamento (CE) n ${ }^{\circ}$ 861/2007 del Parlamento Europeo y del Consejo, de is de julio de 2007, por el que se establece un proceso europeo de escasa cuantía, DOUE Li99 de 31.7.2007.

${ }^{2}$ Reglamento (CE) no I896/2006 del Parlamento Europeo y del Consejo, de 30 de diciembre de 2006, por el que se establece un proceso monitorio europeo, DOUE L 399 de 30.12.2006.

${ }^{3}$ Reglamento (CE) $n^{\circ} 805 / 2004$, por el que se establece un título ejecutivo europeo para créditos no impugnados, DOUE L I43/15 de 30.4.2004.

${ }^{4}$ Directiva 2008/52/CE del Parlamento Europeo y del Consejo, de $2 \mathrm{I}$ de mayo de 2008, sobre ciertos aspectos de la mediación en asuntos civiles y mercantiles, DOUE L I36 de 24.5.2008.

${ }^{5}$ Directiva 20I3/II/UE del Parlamento Europeo y del Consejo, de 2I de mayo de 2013 relativa a la resolución alternativa de litigios en materia de consumo y por la que se modifica el Reglamento (CE) n o 2006/2004 y la Directiva 2009/22/CE. DOUE L I65/63 de I8.6.2013.

${ }^{6}$ Reglamento (UE) $n^{\circ} 524 / 2013$ del Parlamento Europeo y del Consejo de 2I de mayo de 2013 sobre resolución de litigios en línea en materia de consumo y por el que se modifica el Reglamento (CE) n o 2006/2004 y la Directiva 2009/22/CE. DOUE L i65/I de I8.6.2013.

${ }^{7}$ Según el Flash Eurobarómetro sobre la «Actitud de los consumidores frente al comercio transfronterizo y la protección del consumidor» de marzo de $201 \mathrm{I}$, el $79 \%$ de los consumidores europeos manifestaron que estarían más dispuestos a defender sus derechos ante los tribunales si pudieran sumarse a otros consumidores por la misma reclamación. 
masivos podrían resolverse mediante la presentación de un gran número de recursos individuales, debemos reconocer que existen múltiples barreras u obstáculos, como son los costes elevados, procedimientos complejos y dilatados, difícil accesibilidad, etc., que impiden a los consumidores europeos obtener una compensación adecuada y eficaz ${ }^{8}$.

Conviene reflexionar, por tanto, acerca de la posibilidad de interponer las demandas de forma colectiva (agrupadas), para facilitar así el acceso a la justicia de los consumidores, fundamentalmente en aquellos supuestos en los que el coste individual de cada una de ellas disuada a los perjudicados de entablar la acción. La agrupación de todas las demandas en un solo procedimiento colectivo, o incluso la posibilidad de que una sola demanda se presente por una entidad que actúe en nombre de resto de particulares, conllevará una reducción considerable de las costas del proceso, además de otras múltiples ventajas.

Por todo ello, y al haberse demostrado que las prácticas comerciales abusivas que afectan a numerosos consumidores permanecen con frecuencia sin resolver, las instituciones europeas han dedicado parte de su trabajo a la instauración y desarrollo de la acción colectiva como instrumento que contribuya a resolver los problemas de los consumidores en los supuestos de daños masivos. A la labor de las mismas así como a las últimas tendencias en esta materia vamos a dedicar las siguientes líneas.

\section{Las acciones colectivas en Europa}

El imparable aumento de las actividades comerciales transfronterizas ha acentuado la necesidad de mejorar el vigente marco normativo europeo para afrontar los supuestos en los que los consumidores no encuentran una solución a sus conflictos porque los procedimientos de reclamación colectiva regulados en los distintos Estados Miembros no prevén soluciones transfronterizas. Ha llegado el momento en el que se ha considerado necesario actuar a escala de la Unión Europea e instaurar mecanismos mediante los cuales un grupo de consumidores afectados por una misma práctica comercial pueda obtener una compensación eficaz, con independencia del lugar de residencia del comerciante.

\section{II.I. Panorama actual de las acciones colectivas en Europa}

Tras la aprobación de la Directiva 2009/22/CE sobre acciones de cesación ${ }^{9}$, todos los Estados Miembros de la Unión Europea cuentan con procedimientos para que las autoridades competentes en materia de protección de los consumidores y las organizaciones de consumidores puedan interponer con carácter colectivo o representativo

\footnotetext{
${ }^{8}$ Se ha comprobado que la resolución individual de los litigios resulta insuficiente. Su coste y lentitud contribuyen ampliamente a la inaplicación de los derechos de los consumidores, especialmente cuando una misma práctica perjudica a multitud de consumidores (varios miles o, incluso, millones) y cuando el importe del perjuicio individual es relativamente reducido. Además, el desarrollo progresivo de la «sociedad europea» plantea dificultades en cuanto a la determinación del Derecho aplicable, de manera que conviene que los ciudadanos europeos puedan hacer valer sus derechos de manera uniforme. Actualmente, determinados comportamientos abusivos, que se producen en circunstancias idénticas y ocasionan idénticos perjuicios en varios Estados miembros, sólo pueden resarcirse mediante indemnización en los pocos Estados miembros que disponen de un sistema de acción colectiva. En este sentido, vid. Dictamen del Comité Económico y Social Europeo sobre el tema «Definición del papel y del régimen de las acciones colectivas en el ámbito del Derecho comunitario del consumo», DOUE Ci62/I, 25 de junio de 2008.

9 Directiva 2009/22/CE del Parlamento Europeo y del Consejo, de 23 de abril de 2009, relativa a las acciones de cesación en materia de protección de los intereses de los consumidores. DOUE L iIo de 1.05.2009.
} 
demandas de cesación que pongan fin a prácticas ilegales que infrinjan la normativa de protección de los consumidores nacionales y de la Unión Europea. Sin embargo, no todos los Estados Miembros han introducido en sus legislaciones procedimientos de reclamación colectiva de indemnización pues, a diferencia de lo que ocurre con las acciones de cesación, no contamos con ningún mecanismo a nivel europeo que regule la materia.

Los instrumentos para solicitar una reclamación de forma colectiva por un grupo de perjudicados varían considerablemente de un Estado a otro ${ }^{\text {to }}$. Las principales diferencias residen en primer lugar, en su ámbito de aplicación. En algunos países, las acciones colectivas se circunscriben a sectores muy específicos, como ocurre en Alemania, que se aplican únicamente a la recuperación de las pérdidas por inversión de capitales; en Reino Unido, a los daños ocasionados por prácticas contrarias a la competencia y, en Finlandia, al ámbito del consumo. Mientras que otros países cuentan con un alcance más amplio ${ }^{\text {II }}$.

En segundo lugar, la capacidad jurídica para ejercitar estas acciones también varía en los diferentes Estados Miembros. En algunos se ha atribuido la facultad para entablar acciones colectivas a las autoridades públicas (el Defensor del Pueblo en Finlandia), otros reconocen capacidad para actuar a organizaciones privadas como las asociaciones de consumidores (Bulgaria), o a personas físicas y jurídicas (Suecia), etc. En tercer lugar y no por ello menos importante, existen diferentes opciones de participación en las acciones colectivas. Nos encontramos con dos sistemas fundamentalmente: los sistemas de participación voluntaria (modelo opt-in) y los de exclusión voluntaria (modelo opt-out). En el primer grupo se encuadran países como Suecia e Italia, mientras que en el segundo, se integran otros como Portugal y los Países Bajos.

Otras diferencias en el régimen de acciones colectivas de los distintos países de la Unión Europea, atañen a la financiación de las acciones, la distribución de las indemnizaciones y el elenco de sujetos que pueden interponer tales acciones. Tales disparidades han motivado e impulsado las recientes incitativas europeas en el ámbito de las acciones colectivas, pues como la propia Comisión Europea ha señalado en la Consulta «Hacia un planteamiento europeo más coherente del recurso colectivo», la ausencia de un planteamiento coherente de esta materia a nivel de la Unión Europea puede afectar al disfrute de los derechos por los ciudadanos y las empresas y dar lugar a un reconocimiento desigual de estos derechos, lo que resulta más evidente cuando ante litigios transfronterizos nos encontremos. Un marco europeo coherente basado en las diferentes tradiciones nacionales contribuirá a reforzar la acción colectiva, ya sea ésta de cesación o de indemnización ${ }^{\mathrm{I2}}$.

ro Vid. el estudio sobre la «Evaluación de la eficacia de los mecanismos de recurso colectivo en la Unión Europea» de 2009, disponible en:

http://ec.europa.eu/consumers/redress_cons/collective_redress_en.htm\#Studies.

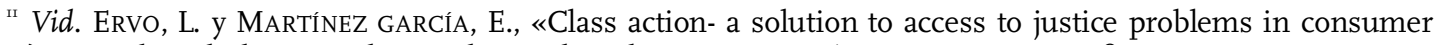
cases? Some thought between the North, South and Europe», ZZPint, I7, 20I2, pág. 208.

${ }^{12}$ Recomendamos la lectura de TZAKAS, D.P., «Effective collective redress in antitrust and consumer protection matters: a panacea or a chimera?», Common Market Law Review, 48-4, 20II, págs. II25-II74. En este artículo se analizan las propuestas europeas en la materia así como los elementos clave para configurar un marco eficaz de las acciones colectivas. 


\section{II.2. Iniciativas europeas}

La Comisión Europea lleva varios años trabajando en el desarrollo de normas europeas sobre acciones colectivas en el ámbito del Derecho de la competencia y de los consumidores. Ejemplo de cuanto decimos es el Libro Verde de I9 de diciembre de 2005 , «Reparación de daños y perjuicios por incumplimiento de las normas comunitarias de defensa de la competencia $»^{\text {I3 }}$ y su correspondiente Libro Blanco «Acciones de daños y perjuicios por incumplimiento de las normas comunitarias de defensa de la competencia» de 2 de abril de 2008 , en el cual ya se incluían propuestas sobre acciones colectivas específicas contra las prácticas contrarias a la normativa de competencia ${ }^{\mathrm{T} 4}$.

En el ámbito del consumo, se publicó ese mismo año el Libro Verde sobre acciones colectivas de los consumidores ${ }^{15}$, con el fin de evaluar la situación de estos mecanismos y tratar de aportar soluciones que ayuden a superar los obstáculos que puedan presentarse ${ }^{\mathrm{r} 6}$. Asimismo, el Comité Económico y Social Europeo emitió un Dictamen sobre el tema: «Definición del papel y del régimen de las acciones colectivas en el ámbito del Derecho comunitario del consumo ${ }^{17}$ en donde se subrayaba el objetivo de crear una acción colectiva comunitaria que permitiera acceder a la justicia a todos los consumidores, cualquiera que sea su nacionalidad, situación económica y perjuicio individual sufrido y evitara contradicciones entre la jurisprudencia de los órganos jurisdiccionales de los Estados Miembros que tengan que dirimir litigios similares.

En enero del 20II, la Comisión Europea lazó una Consulta Pública: «Hacia un planteamiento europeo más coherente del recurso colectivo» ${ }^{\mathrm{r}}$, con el fin de alcanzar un enfoque coherente de las acciones colectivas de la Unión Europea y determinar sus principios jurídicos comunes así como examinar su inserción en el sistema jurídico de la Unión Europea y en los ordenamientos jurídicos de sus 27 Estados miembros. La Consulta suscitó una amplia respuesta, coincidiendo la mayor parte de los interesados en la conveniencia de establecer unos principios comunes a nivel europeo.

Un año después, el 2 de febrero de 2012, el Parlamento Europeo publicó la Resolución «Hacia un planteamiento europeo coherente del recurso colectivo» ${ }^{\text {19 }}$. En ella, el Parlamento acoge con satisfacción la labor de la Comisión en busca de una solución coherente europea de las acciones colectivas e insiste en que toda propuesta en esta materia consista en un instrumento jurídico horizontal que incluya un conjunto común de principios.

\footnotetext{
${ }^{13}$ COM (2005) 672 final

${ }^{{ }^{14}}$ COM (2008) I65 final. En esta materia, debemos destacar la reciente Propuesta de Directiva relativa a determinadas normas por las que se rigen las demandas por daños y perjuicios por infracciones de las disposiciones del Derecho de la competencia de los Estados miembros y de la Unión Europea. COM (2OI3) 404 final, de II.6.2013, 2013/0185 (COD).

${ }^{15} \mathrm{COM}(2008) 794$ final.

${ }^{16}$ Hemos traducido el término «collective redress» como «acción colectiva» en lugar de «recurso colectivo»; término este último que no consideramos apropiado en nuestra tradición jurídica, a pesar de ser el utilizado en las traducciones oficiales de los documentos de la Unión Europea que estamos analizando.

${ }^{17}$ Aprobado los días I3 y I4 de febrero de 2008. DOUE Ci62/I, de 25 de junio de 2008.

${ }^{18} \mathrm{http}$ ///ec.europa.eu/dgs/health_consumer/dgs_consultations/ca/collective_redress_consultation_en.htm

${ }^{19}$ DOUE C 239 E/32 de 20.08.20I3. Vid. el Informe previo del Parlamento de I2 de enero de 20I2, «Hacia un planteamiento europeo coherente del recurso colectivo» (20II/2089(INI)).
} 
Finalmente, el in de junio de 2013 la Comisión ha publicado la Comunicación al Parlamento Europeo, al Consejo, al Comité Económico y Social Europeo y al Comité de las Regiones, «Hacia un marco horizontal europeo de recurso colectivo» (en adelante, Comunicación) ${ }^{20}$. Esta Comunicación ha venido acompañada de una Recomendación sobre los principios comunes aplicables a los mecanismos de acción colectiva, tanto judicial como extrajudicial, de cesación o de indemnización en los Estados Miembros en caso de violación de los derechos reconocidos por el Derecho de la Unión (en adelante, Recomendación) 2 $^{21}$ La finalidad de ambos documentos reside en tratar de configurar un marco que permita a las partes perjudicadas obtener una indemnización en caso de daños masivos causados por infracciones de los derechos reconocidos por el Derecho de la Unión, al mismo tiempo que se establecen las garantías procesales necesarias para evitar los litigios abusivos.

En la Comunicación se exponen las principales opiniones vertidas en la Consulta Pública así como la posición de la Comisión Europea respecto de algunos de los aspectos esenciales de las acciones colectivas. Por su parte, en la Recomendación se defiende un planteamiento o enfoque horizontal que evite el riesgo de iniciativas europeas sectoriales no coordinadas, por lo que su contenido será también aplicable al Derecho de competencia ${ }^{22}$. Además, se recomienda que todos los Estados miembros dispongan de sistemas de acción colectiva a nivel nacional que respeten los mismos principios básicos en toda la Unión, teniendo en cuenta las tradiciones jurídicas ${ }^{23}$.

\section{Tutela judicial de las acciones colectivas}

Vamos a analizar a continuación las principales cuestiones procesales de los procesos colectivos que desde las instituciones europeas, a modo de principios o pautas, se recomienda implantar ${ }^{24}$. Al mismo tiempo, iremos exponiendo el régimen jurídico que en esta materia ha adoptado el legislador español. En primer lugar, nos detendremos en la tutela judicial de las acciones colectivas, mientras que dedicaremos el último apartado de este trabajo, a los mecanismos extrajudiciales de solución de conflictos colectivos.

\section{III.I. ¿Qué se entiende por acciones colectivas?}

Cuando un determinado o indeterminado número de personas sufre perjuicios derivados de una misma infracción cometida por un mismo agente, sus demandas pueden

\footnotetext{
${ }^{20} \mathrm{COM}(2013)$ 40I final.

${ }^{21}$ DOUE L 201/60 de 26.07.2013.

${ }^{22}$ La Comisión considera que la acción colectiva es un mecanismo procesal que puede resultar pertinente para las políticas desarrolladas por la Unión Europea en ámbitos distintos de la competencia o la protección de los consumidores. Buenos ejemplos a ese respecto son los servicios financieros, la protección del medio ambiente, la protección de datos o la lucha contra la discriminación. Por ello la Comisión considera necesario adoptar un enfoque horizontal.
}

${ }^{23}$ Tras la publicación de la Recomendación, los Estados miembros disponen de dos años para incorporar los principios recogidos en la misma en sus sistemas nacionales, es decir, a más tardar el 26 de julio de 2015 . A partir de la experiencia práctica, la Comisión evaluará, cuatro años después de su publicación (26 de julio de 20I7), si se proponen nuevas medidas legislativas para consolidar y reforzar el enfoque horizontal que pretende.

${ }^{24}$ Son numerosas las cuestiones procesales que plantean las acciones colectivas. No abordamos todas ellas, pues excedería del objeto del presente trabajo, sino que nos limitamos a analizar aquéllas sobre las cuales las instituciones comunitarias están tratando de dirigir unas pautas o principios comunes para todos los Estados miembros. 
agruparse en un único procedimiento colectivo, siendo asimismo posible que un órgano o entidad representativa actúe en nombre del interés general e interponga una sola demanda, lo que simplificará enormemente el proceso y reducirá los gastos que podría conllevar la tramitación de manera separa de cada una de las demandas individuales.

La acción colectiva no es un concepto novedoso en el marco de la Unión Europea. Diferentes normas, tales como la Directiva sobre acciones de cesación, ya contemplaban la adopción de medidas cautelares colectivas en determinados ámbitos. Como ha proclamado la Comisión Europea en su Comunicación «Hacia un marco horizontal europeo de recurso colectivo», la acción colectiva es un mecanismo procesal que, por motivos de economía procesal y/o eficacia ejecutoria permite la agrupación de numerosas pretensiones jurídicas similares en una única demanda, de modo que facilita el acceso a la justicia, especialmente en los casos donde los perjuicios individuales son tan limitados que los demandantes potenciales podrían considerar superfluo interponer una acción. Además, este mecanismo refuerza el poder de negociación de los demandantes potenciales y contribuye a la administración eficaz de la justicia, evitando la multiplicación de procesos por pretensiones derivadas de una misma infracción. En todo caso, la regulación de estas acciones no impide la existencia de acciones individuales ejercitadas por particulares.

Debemos destacar la doble vertiente de las acciones colectivas, pues según el tipo de pretensión con la que nos encontremos, pueden adoptar la forma de acción colectiva de cesación, mediante la cual se persigue el cese de una práctica ilegal, o de acción colectiva de indemnización, con la que se pretende la obtención de una indemnización por los daños y perjuicios ocasionados. Ambas acciones podrán interponerse en el supuesto en el que se produzca un «daño masivo». Por ello, más detenidamente, la Comisión Europea ha definido la acción colectiva como el: «i) mecanismo jurídico que garantiza la posibilidad de solicitar la cesación de un comportamiento ilegal, de forma colectiva por dos o más personas físicas o jurídicas o por una entidad capacitada para entablar una acción de representación (recurso colectivo de cesación), ii) mecanismo jurídico que garantiza la posibilidad de reclamar una indemnización de forma colectiva por dos o más personas físicas o jurídicas que afirmen haber sido perjudicadas en caso de daños masivos o por una entidad capacitada para entablar una acción de representación (recurso colectivo de indemnización) $\gg^{25}$. A pesar de esta doble vertiente, dada la complejidad de la materia y la limitación de extensión de este trabajo, nos vamos a ceñir a estudiar el segundo grupo de acciones colectivas, es decir, las de indemnización; lo que no impide que sean múltiples las ocasiones en las que lo dicho para estas acciones sea trasladable a las acciones de cesación.

En el ordenamiento español, las acciones colectivas reguladas en la Ley de Enjuiciamiento Civil se ciñen a la protección de los consumidores y usuarios. Esta norma procesal diferencia claramente entre dos clases de intereses, los intereses colectivos que son los de aquellos perjudicados por un hecho dañoso, sean un grupo de consumidores o usuarios, cuyos componentes estén perfectamente determinados o sean fácilmente determinables (art. II.2 LEC), de los intereses difusos que corresponden a los perjudicados por un hecho dañoso, sean una pluralidad de consumidores o usuarios, indeterminada o de difícil determinación (art. II.3 LEC).

\footnotetext{
${ }^{25}$ Punto II.3.a) de la Recomendación de la Comisión. Asimismo, define los daños masivos como la «situación en la que dos o más personas físicas o jurídicas afirman haber sufrido un perjuicio como consecuencia de una pérdida causada por una misma actividad ilegal de una o varias personas físicas o jurídicas».
} 
Nuestra norma procesal no instaura un procedimiento ad hoc específico para la tutela de los derechos e intereses colectivos de los consumidores, pero sí establece diversas normas especiales cuando lo estima oportuno. De este modo, los artículos 6, II, I5, 76, 2I7, 22I, 222, 249, 250, 256.6 y 5I9 LEC, regulan aspectos tales como, la legitimación, el llamamiento al proceso, la acumulación de acciones y de procesos, los efectos de la sentencia y la ejecución. No vamos a analizar todos ellos, pues nos limitamos a destacar las últimas tendencias y pautas que las instituciones europeas nos recomiendan, por lo que cuestiones tan importantes como la diligencia preliminar de determinación de los integrantes del grupo, la sentencia «colectiva» y su ejecución no van ser debatidas ${ }^{26}$.

\section{III.2. Legitimación de las partes y control judicial}

En lo que a la legitimación atañe, la Comisión Europea considera (punto 6 de la Recomendación) que este tipo de acciones solo deben poder ser interpuestas por entidades previamente designadas oficialmente, o por entidades que hayan sido acreditadas ad hoc por las autoridades nacionales de un Estado Miembro o por los órganos jurisdiccionales para una determinada acción de representación ${ }^{27}$. Se garantiza de este modo, que exista un control manifiesto sobre quiénes puedan presentar tales demandas ${ }^{28}$.

Estas entidades deben cumplir determinados criterios establecidos por ley. La Comisión recomienda que, como mínimo, las entidades no tengan ánimo de lucro, exista una relación directa entre los objetivos principales de la entidad y los derechos reconocidos por el Derecho de la Unión que la acción que se interpone considere violados y por último, tenga capacidad suficiente en términos de recursos financieros, recursos humanos y conocimientos jurídicos para representar a múltiples demandantes y defender sus intereses.

El legislador español ha tomado la decisión de que sean personas jurídicas constituidas y legalmente habilitadas las que puedan llevar estos intereses a juicio ${ }^{29}$. De modo que, la legitimación para pretender la tutela de los intereses colectivos corresponde a las asociaciones de consumidores y usuarios, a las entidades legalmente constituidas que tengan por objeto la defensa o protección de éstos, así como a los propios grupos de

\footnotetext{
${ }^{26}$ Respecto a la diligencia del art. 256 LEC nos remitimos a BARONA VILAR, S., «Diligencia preliminar específica de determinación de los integrantes de grupo afectados (ante la expectativa de un proceso futuro para la defensa de los intereses colectivos)», en AA.VV, Tutela de los consumidores y usuarios en la nueva Ley de Enjuiciamiento Civil, (coord. BARONA VILAR), Valencia, Tirant lo Blanch, 2002, págs. I47-I88. En lo que a la sentencia se refiere a CALDERÓN CUADRADO, P., «La sentencia dictada en ejecución en procesos promovido por asociaciones de consumidores y usuarios», Tutela de los consumidores y usuarios..., cit., pp. 3I5-364. De la ejecución, vid. MARTínez GARCíA, E., «Sentencia de I5 de julio de 20IO: El concepto de interés difuso. La legitimación colectiva por interés difuso. Ejecución de sentencias dictadas en procesos colectivos», Cuadernos Civitas de Jurisprudencia Civil, 86, $201 \mathrm{I}$.

${ }^{27}$ La acción de representación viene definida en el punto 3 de la Recomendación como la «acción interpuesta por una entidad representante, una entidad acreditada ad hoc o una autoridad pública, en representación y en nombre de dos o más personas físicas o jurídicas que declaren correr el riesgo de sufrir daños o haber sufrido daños como consecuencia de daños masivos, cuando dichas personas no sean partes del procedimiento».

${ }^{28}$ OtERo Crespo, M., «Las acciones colectivas en Europa: ¿Un paso adelante?», Boletín CeDe UsC.-. Editorial, noviembre 20I3, pág. 4 .

${ }^{29}$ Lo que, como señala LóPEZ JIMÉNEZ, ha sido discutido por restrictivo por algún sector doctrinal que sugiere que puedan ser afectados aislados, o sujetos no afectados, pero que acrediten un interés suficiente (por ejemplo, despachos de abogados), los que ostenten legitimación para iniciar estos procedimientos. Vid. LÓPEZ JIMÉNEZ, J.M ${ }^{\mathrm{a}}$., «Las acciones colectivas como medio de protección de los derechos e intereses de los consumidores», Diario La Ley, 6852, enero 2008, año XXIX, pág. Io.
} 
afectados (art. II.2 LEC), mientras que la legitimación para demandar en juicio la defensa de los intereses difusos resulta más restrictiva y corresponde exclusivamente a las asociaciones de consumidores y usuarios que, conforme a la Ley, sean representativas (art. II.3 LEC) $)^{30}$.

Sumamente importante resulta en los procesos colectivos el papel del juez. Consideramos que es él quien debe controlar tanto la legitimación de las partes como la admisibilidad de la acción colectiva, cerciorándose de que efectivamente se trata de una causa que se vincula a la vulneración de unos derechos colectivos ${ }^{31}$. En esta línea, ya en el Libro Verde en su día se manifestó que los Estados Miembros deben garantizar que un juez $\mathrm{u}$ órgano similar tenga facultades discrecionales consistentes en un control previo de admisibilidad de las posibles acciones colectivas, con objeto de confirmar que se satisfacen los criterios de admisibilidad y que la acción puede ejercitarse. Con el fin de evitar la posibilidad de abuso de este tipo de acciones, hay varios elementos que pueden actuar como salvaguardia y contribuir a prevenir la presentación de denuncias injustificadas. El juez puede desempeñar un papel esencial, decidiendo si una denuncia colectiva es injustificada o por el contrario, es admisible. En todo caso, la certificación de la entidad representante funciona ya como un primer control de acceso.

\section{III.3. Constitución de la parte demandante}

Una decisión clave a la hora de configurar las acciones colectivas consiste en determinar el procedimiento para integrarse o quedar fuera de las mismas. Como ya hemos mencionado en líneas anteriores, existen dos modelos: el de participación voluntaria (opt-in) y el de exclusión voluntaria (opt-out).

En el primero de ellos, en el de participación voluntaria, el grupo incluye únicamente a aquellas personas (físicas o jurídicas) que deciden optar expresamente por adherirse a la acción colectiva. En este sentido, la sentencia que finalmente se adopte será vinculante para todos los miembros que formen parte del grupo. De este modo, los demás sujetos potencialmente perjudicados por similar o idéntica infracción pero que no fueron parte en el proceso, seguirán ostentando la facultad de interponer una demanda individual por los daños y perjuicios sufridos, no viéndose afectados por la cosa juzgada de la resolución. Por su parte, en el segundo modelo, el de exclusión voluntaria, el grupo se compone, a diferencia del anterior, de todos los individuos que pertenecen al grupo por haber sufrido daños o perjuicios derivados de la misma o similar infracción, salvo en el supuesto en el que opten expresamente por desvincularse del mismo. En este caso, la sentencia será vinculante para todos los sujetos que pertenecen al grupo definido excepto para aquéllos que expresamente se excluyeron.

\footnotetext{
${ }^{30}$ Por su parte, el Ministerio Fiscal y las entidades habilitadas a las que se refiere el artículo 6.I.8 LEC están legitimadas para el ejercicio de la acción de cesación para la defensa de los intereses colectivos y difusos de los consumidores y usuarios (art. II.4 LEC).

${ }^{31}$ Este tipo de procesos en los que se ven afectados una pluralidad de consumidores o usuarios se caracterizan por la dispersión geográfica por Europa de sus afectados, razón por la cual se viene apreciando la conveniencia de que sea la Audiencia Nacional el órgano competente para conocer en nuestro país de estos asuntos. En este sentido, MARTÍNEZ GARCíA, E., «Las acciones colectivas de consumo en la Unión Europea», en Gómez Colomer, J.L., Barona Vilar, S. y Calderón Cuadrado, P. (coords.), El Derecho Procesal español del siglo XX a golpe de Tango, Valencia, Tirant lo Blanch, pág. I324.
} 
Cada uno de estos sistemas presenta sus ventajas e inconvenientes ${ }^{32}$. Los sistemas de opt-in preservan en mayor medida la libertad del individuo para acceder al proceso pero pueden llegar a ser extremadamente laboriosos y costosos para, por ejemplo, las organizaciones de consumidores que tendrán previamente que identificar a los consumidores afectados. El sistema de opt-out podría mitigar las dificultades mencionadas y la complejidad procesal, sin embargo en Europa se posee una visión negativa del mismo por el riesgo de litigio excesivo que han ocasionado en Estados Unidos las denominadas «class actions». Por ello, entre otras razones, finalmente la Comisión Europea ha optado por inclinarse en su Recomendación por el método de participación voluntaria (opt-in) ${ }^{33}$. Toda excepción a este principio debe establecerse por ley o por resolución judicial y estar debidamente justificada por motivos de correcta administración de la justicia. De modo que, quienes aleguen haber sufrido daños en un mismo supuesto de «daños masivos» deben poder adherirse a la parte demandante en cualquier momento antes de que se dicte la resolución definitiva o el asunto se resuelva válidamente de otra manera. Asimismo, todo aquél que pertenezca al grupo demandante deberá poder retirarse en cualquier momento antes de que se decida el conflicto.

Aunque la Ley de Enjuiciamiento Civil española no prevea expresamente ningún mecanismo de opt-out, parece ser que nuestro sistema de acciones colectivas se asemeja en mayor medida al modelo de exclusión. En este sentido, del artículo 222.3 LEC se desprende que la cosa juzgada despliega sus efectos no sólo respecto de los litigantes concretos, sino respecto de todos y cada uno de los consumidores y usuarios titulares de los derechos debatidos, hayan sido o no parte en el proceso. Entendemos que lo que ha pretendido con esto el legislador español, es que no puedan incoarse más procesos (colectivos o individuales) contra ese demandado por los mismos hechos.

Ahora bien, para que resulte constitucionalmente legítima la extensión de los efectos de la sentencia a todos los consumidores perjudicados por el hecho dañosos que forman parte del ámbito subjetivo del proceso, con la consiguiente limitación en cuanto al posible ejercicio de acciones con posterioridad, será necesario como señala GASCóN INCHAUSTI que los consumidores tenga conocimiento de la existencia del proceso, lo que se cumple con el llamamiento colectivo al proceso de los sujetos que se verán afectados por la extensión ultra partes de la cosa juzgada de la sentencia. Además, sería igualmente necesario conceder a los consumidores la facultad de excluirse del ámbito del proceso. Aunque la LEC no contempla expresamente ningún mecanismo para que se pueda proceder a tal exclusión, entendemos junto al mencionado autor, que dicha exclusión será posible sobre la base del artículo I5 LEC, que regula el llamamiento para que los consumidores hagan valer su derecho o interés individual, de modo que cuando así lo consideren, la forma de hacerlo valer consistirá en desvincularse de ese proceso colectivo ${ }^{34}$.

\footnotetext{
${ }^{32}$ Recomendamos la lectura del Dictamen del Comité Económico y Social Europeo «Definición del papel y del régimen de las acciones colectivas en el ámbito del Derecho comunitario del consumo», DOUE Ci62/I, en cuya propuesta $7^{\text {a }}$ se analizan detenidamente las ventajas y los inconvenientes de uno u otro sistema.

${ }^{33}$ En idéntico sentido, el Parlamento Europeo en su Resolución de 2 de febrero de 20I2, manifiesta que el enfoque europeo de la acción colectiva debe basarse en el principio de adhesión (opt-in), en el que las víctimas son identificadas claramente y toman parte en el procedimiento solo si indican expresamente su deseo de hacerlo, a fin de evitar posibles abusos.

${ }^{34}$ Cfr. Gascón InChausti, F., Tutela judicial de los consumidores $y$ transacciones colectivas, Navarra, Thomson Reuters-Civitas, 20I0, págs. I25 y I26. Considera este autor que el legislador puede, mediante la atribución de legitimación extraordinaria, permitir que ciertos sujetos hagan valer judicialmente los derechos de otros, sin
} 


\section{III.4. Suministro de información}

Como acabamos de mencionar, para justificar la extensión subjetiva de la cosa juzgada de las resoluciones judiciales que resuelven los procesos colectivos, consideramos de trascendental importancia la necesaria difusión de información de la acción colectiva, de modo que se ofrezca la posibilidad de intervenir a los sujetos sobre los que recaerán los efectos de la sentencia, pues su ausencia podría provocar situaciones injustas como sería la de aquel individuo que se encuentra vinculado por una resolución que se ha dictado sin su previo conocimiento. Esta información resulta imprescindible para asegurar el acceso a la tutela judicial de quienes puedan alegar haber resultado perjudicados por una presunta infracción idéntica o similar.

Debemos detenernos pues, en la cuestión fundamental atinente al debido suministro de información. Deviene indispensable la configuración de un sistema que ofrezca, en la medida de lo posible, información sobre la existencia de procedimientos en los que se ha ejercitado una acción colectiva a todas las posibles víctimas implicadas o al menos, al máximo número de perjudicados, de manera que éstos conozcan los derechos y obligaciones que ostentan. Por ello, como mecanismo que garantice la existencia de una información accesible, se defiende desde las instituciones europeas, la creación de registros nacionales de acciones colectivas a los que pueda acceder cualquier persona interesada.

Para poder proceder a agrupar las demandas en una misma acción colectiva, los sujetos en cuestión deben ser conscientes de haber sido perjudicados por la misma o similar infracción ilegal así como de la facultad o derecho del que gozan para interponer una demanda colectiva (o adherirse a la misma); cuestión que será más dificultosa en los supuestos en los que nos encontremos con víctimas de diferentes Estados Miembros. Como ha señalado el Parlamento Europeo en su Resolución de 2 de febrero de 20I2, hay que descartar un sistema de demandas colectivas en el que las víctimas no estén identificadas antes del pronunciamiento de la sentencia por ser contrario al ordenamiento jurídico de muchos Estados Miembros y violar los derechos de las víctimas que pudieran participar en el proceso sin saberlo y para los que, a pesar de ello, sería obligatoria la resolución judicial.

Conscientes de la relevancia de proporcionar la información mencionada, no debemos sin embargo olvidar, que asimismo se debe tratar de evitar que se perjudique de manera indebida la reputación de la parte demandada preservando su presunción de inocencia, por lo que las normas relativas al suministro de información a los demandantes potenciales deben generar equilibrio entre la libertad de expresión y el derecho de acceso a la información por un lado, y la protección de la reputación del demandado, por otro ${ }^{35}$. Es por ello que la Comisión, en su Recomendación (puntos io y II), si bien dispone que se debe garantizar que los demandantes puedan difundir información sobre la presunta violación de derechos reconocidos y su intención de interponer la acción colectiva, también señala que los métodos de difusión de información deben tener en cuenta las

necesidad de contar con su autorización expresa; ahora bien, lo que no le parece compatible con nuestro sistema de tutela es que se impida a un sujeto disponer de su derecho subjetivo por medio de un acto expreso, y esto es lo que sucedería si se le negara la facultad de excluir su derecho subjetivo del ámbito del proceso.

${ }^{35}$ No puede subestimarse el hecho de que anunciar (por ejemplo, en televisión) la intención de incoar una acción colectiva puede tener repercusiones negativas para la reputación del demandado, con posibles efectos perjudiciales para su situación económica. COM (20I3) 40I final, pág. I4. 
circunstancias particulares del caso de daños masivos de que se trate y el derecho a la protección de la reputación o del valor de la empresa del demandado.

En el ordenamiento español, el régimen de llamamiento e intervención de los consumidores individuales en estos procesos viene regulada en el artículo I5 LEC ${ }^{36}$. En este precepto se impone al secretario judicial, la obligación de proceder a un llamamiento, publicando la admisión de la demanda en medios de comunicación con difusión en el ámbito territorial en el que se haya manifestado la lesión de los derechos o intereses, a todos los consumidores o usuarios afectados con vistas a permitir su intervención en el proceso.

En el supuesto en el que los perjudicados estén determinados o sean de fácil determinación, la parte actora les deberá comunicar previamente la presentación de la demanda (art. I5 .2 LEC), tras lo cual podrán intervenir en el proceso en cualquier momento; aunque solo podrán realizar los actos procesales que no hubieren precluido ${ }^{37}$. Mientras que si los perjudicados son personas indeterminadas o de difícil indeterminación, se suspenderá el proceso (no más de dos meses), reanudándose el mismo con la intervención de todos los consumidores que han acudido al llamamiento, no admitiéndose la personación individual posterior de consumidores, los cuales únicamente podrán hacer valer sus derechos una vez recaída sentencia, conforme a los artículos 22I y 5I9 LEC.

\section{III.5. Financiación}

Otro de los temas que se ha abordado en la Recomendación y en la Comunicación de la Comisión Europea, es el de la financiación de los procedimientos de las acciones colectivas, pues el hecho de que sean muchas las partes demandantes, conlleva inevitablemente que los costes alcancen unas cuotas elevadas. Es por ello que la Comisión reconoce, que si bien es cierto que la escasez de fondos no debe limitar el acceso a la justicia, también lo es que los mecanismos de financiación de las acciones colectivas no deben crear incentivos para los litigios abusivos, por lo que plantea dos soluciones:

a) Financiación por terceros. La financiación por aquéllos que no son parte en el proceso presenta el riesgo de incentivar litigios abusivos, por lo que la Comisión considera que es un aspecto que debe regularse, de modo que se sujete a una serie de condiciones y se adopten las medidas adecuadas para que no dé lugar ni a abusos del sistema ni a conflictos de intereses. En este sentido, se pretende que la parte demandante declare al órgano judicial, el origen de los fondos que sufragan la acción. Y en el caso de que la acción colectiva esté financiada por un tercero privado, éste tendrá prohibido: a) intentar influir en las decisiones procesales de la parte demandante, incluidas las transacciones, b) financiar una acción colectiva contra un demandado que sea un competidor del proveedor de fondos

${ }^{36}$ Sobre la materia, recomendamos la lectura de Planchadell Gargallo, A., «La intervención de los consumidores afectados en los procesos colectivos», en Gómez Colomer, J.L., BARONA Vilar, S. y CALDERón Cuadrado, P. (coords.), El Derecho Procesal español del siglo XX a golpe de Tango, cit., págs. 76I-78I.

${ }^{37} \mathrm{Si}$ efectivamente se produce esta comunicación y todos los perjudicados han sido informados, el trámite de llamamiento deviene innecesario. En todo caso, queda al arbitrio judicial la elección del medio más adecuado para dar mayor difusión a los afectados. Respecto a éstos, no parece que el legislador se refiera a la notificación a través de boletines oficiales, sino que opta por los medios de comunicación social y no sólo los tradicionales (prensa escrita, radio, televisión) sino también las nuevas técnicas y medios tecnológicos. GonZÁlez PILLADO, E., La intervención voluntaria de terceros en el proceso civil, Valencia, Tirant lo Blanch, 2006, pág. 92. 
o contra un demandado del que dependa el proveedor de fondos y, c) exigir intereses excesivos sobre los fondos prestados ${ }^{38}$.

b) Financiación pública. La Comisión no considera, sin embargo, necesario recomendar una ayuda directa a partir de fondos públicos, pues si el órgano jurisdiccional dictamina que los daños se han producido efectivamente, la parte damnificada será indemnizada por la parte vencida en el litigio y se le reembolsarán las costas jurídicas.

En todo caso, la Comisión recomienda que se aplique el principio de «quien pierde paga», por medio del cual el que pierde el juicio es quien debe sufragar las costas judiciales. Efectivamente, consideramos que este principio garantiza el inicio de acciones que podríamos calificar de «temerarias».

\section{III.6. Litigios transfronterizos}

Debe poderse interponer una acción colectiva única ante una misma jurisdicción cuando el conflicto afecte a personas físicas o jurídicas de varios Estados Miembros. En este sentido, las normas procesales europeas, especialmente las correspondientes a la ley aplicable, deben aplicarse de forma eficiente a este tipo de acciones. Del mismo modo, la resolución que se adopte tendrá que ser ejecutiva en todos los Estados ${ }^{39}$.

Por este motivo se ha planteado la cuestión de si las actuales normas europeas sobre la competencia judicial, el reconocimiento y la ejecución de resoluciones judiciales y la ley aplicable cumplen de forma suficiente este objetivo o si, por el contrario, un planteamiento europeo coherente de la acción colectiva exigiría normas específicas adicionales sobre la competencia judicial o la ley aplicable ${ }^{40}$. Al respecto, la Comisión finalmente ha considerado que debe recurrirse a las normas recogidas en el Reglamento (CE) $n^{\circ} 44 / 200$, relativo a la competencia judicial, el reconocimiento y la ejecución de resoluciones judiciales en materia civil y mercantil (el Reglamento Bruselas $\mathrm{I}^{4 \mathrm{~T}}$ ), en toda su extensión.

\section{Las ADR y las acciones colectivas}

Siendo partidarios de las fórmulas ADR (Alternative Dispute Resolution), que consideramos pueden convertirse en una poderosa herramienta para los consumidores, vamos a dedicar las líneas que prosiguen a la posibilidad de solucionar de una manera consensuada los litigios colectivos. Nos cuestionamos pues, si este tipo de conflictos pueden resolverse extrajudicialmente, bien sea con la intervención de un tercero (como sería el caso de la mediación ${ }^{42}$ o el arbitraje), bien sea sin tal intervención (como ocurre con las meras

\footnotetext{
${ }^{38}$ Punto I5 Recomendación.

${ }^{39}$ Respecto a la eficacia extraterritorial de las acciones colectivas, recomendamos la lectura de la monografía de CARbAllo PiñEIRo, L., Las acciones colectivas y su eficacia extraterritorial, Santiago de Compostela, Universidad de Santiago de Compostela, 2009.

${ }^{4 \circ}$ Vid. Consulta pública: «Hacia un planteamiento europeo más coherente del recurso colectivo» (véase para referencia de acceso en línea la nota al pie $\mathrm{i} 8$ ).

${ }^{41}$ Modificado por el Reglamento (CE) n $n^{\circ}$ 1215/2012, que entrará en vigor el io de enero de 20I5. DOUE L 35I de 20.12.20I2.

${ }^{42}$ Recordamos, sin embargo, que tanto la Directiva de Mediación en asuntos civiles y mercantiles como la Ley española 5/20I2, de 6 de julio, de mediación en asuntos civiles y mercantiles excluyen expresamente de su ámbito de aplicación la mediación en los litigios de consumo.
} 
transacciones o arreglos amistosos entre las partes). Vamos a observar cómo, si bien los procedimientos alternativos de solución de conflictos pueden resultar un medio eficaz a la hora de obtener una reparación en caso de daños masivos, son múltiples los óbices que dificultan este planteamiento.

\section{IV.I. Propuestas europeas}

Para abordar esta cuestión, debemos partir de la regulación prevista en el seno de la Unión Europea relativa a los diferentes medios de resolución extrajudicial de conflictos. A nivel comunitario, contamos con la Directiva 2008/52/CE de 2I de mayo de 2008, sobre ciertos aspectos de la mediación en asuntos civiles y mercantiles; la Directiva 2013/II/UE de 2I de mayo de 2013 relativa a la resolución alternativa de litigios en materia de consumo y el Reglamento $\mathrm{n}^{\circ}$ 524/2013 del Parlamento Europeo y del Consejo de 2I de mayo de 2013 sobre resolución de litigios en línea en materia de consumo ${ }^{43}$. A pesar de que estas normas han sido redactadas sin tener presentes las acciones colectivas de los consumidores, entendemos que sus principios también pueden aplicarse a los mecanismos de solución alternativa de conflictos colectivos. En este sentido, la mayor parte de los mecanismos ADR previstos en las diferentes legislaciones de la Unión Europea se refieren esencialmente a denuncias individuales, pero ello no impide que, bajo determinados condicionantes y cautelas, puedan trasladarse al ámbito de las demandas colectivas.

Consciente la Comisión Europea de que los mecanismos de solución consensuada de litigios pueden desempeñar un útil papel complementario en el ámbito de las acciones colectivas, ha considerado útil dar un paso más y recomendar a los Estados Miembros que desarrollen mecanismos alternativos de solución de litigios colectivos. En su Recomendación de II de junio de 2013, insta a los Estados a que aseguren que se anime a las partes de los litigios surgidos en supuestos de daños masivos a resolver la cuestión indemnizatoria de forma consensuada o extrajudicial, tanto en la fase previa al juicio como durante el mismo ${ }^{44}$.

Se planteó en el Libro Verde sobre acciones colectivas de los consumidores (cuestión I6), si la solución consensual colectiva de conflictos debía ser una fase obligatoria en los asuntos judiciales de indemnizaciones colectivas, es decir, si podía convertirse en un requisito legal previo a la acción judicial. Al respecto, el Parlamento Europeo en su Resolución de 2 de febrero de 2012 , si bien propuso que el juez que realice el control previo de admisibilidad de una demanda colectiva goce también de la facultad de ordenar a las partes el intento de alcanzar una solución consensuada de la controversia colectiva antes de presentar la demanda, subrayó no obstante, que estos mecanismos deben seguir siendo,

${ }^{43}$ Con anterioridad a tales instrumentos normativos, la Comisión Europea publicó dos Recomendaciones para facilitar la solución alternativa de conflictos. La Recomendación 98/257/CE relativa a los principios aplicables a los órganos responsables de la solución extrajudicial de los litigios en materia de consumo, (DOUE L II5 de I7.4.I998) y la Recomendación 200I/3I0/CE relativa a los principios aplicables a los órganos extrajudiciales de resolución consensual de litigios en materia de consumo, DOUE L iog de I9.4.200I.

${ }^{44}$ Como señala MARTínez GarCíA, resulta cuanto menos paradójico el cambio de perspectiva, cuando la propia Directiva de Mediación en asuntos civiles y mercantiles excluye expresamente la mediación en litigios de consumo por razón del peligroso desequilibrio existente en una mesa de negociación entre empresario y consumidor. Sin embargo, manifiesta esta autora, es una realidad que negociar «colectivamente» consumidores frente a un empresario cambia cualitativa y cuantitativamente el eje de fuerzas y se puede, entonces, hablar de un equilibrio de poderes; vid. MARTínEZ GARCÍA, E., «Las acciones colectivas de consumo en la Unión Europea», cit., pág. I330. 
como su propio nombre indica, una alternativa a la vía jurisdiccional y no una condición previa $^{45}$. Entendemos, por tanto, que este tipo de soluciones consensuales no pueden imponerse, por lo que, en modo alguno, debe considerarse un primer paso obligatorio antes de ir a los tribunales. Esta alternativa que se puede ofrecer a las partes debe mantener su carácter facultativo, en cumplimiento de la normativa europea vigente en la materia, por lo que acudir a tales modalidades de resolución de conflictos dependerá en última instancia del consentimiento de las partes.

La anterior afirmación no debe reprimir a los jueces que conozcan de las acciones colectivas a que inviten o incluso inciten a las partes de la controversia a buscar una solución colectiva consensuada, en la línea de lo dispuesto en la Directiva sobre ciertos aspectos de la mediación en asuntos civiles y mercantiles (art. 5), que proclama que el órgano jurisdiccional que conozca de un asunto puede proponer a las partes que recurran a la mediación para solucionar el litigio.

Además de la ya conocida por todos fuerza ejecutiva de los laudos arbitrales, la Directiva sobre mediación proclama que el órgano jurisdiccional ha de otorgar fuerza ejecutoria al contenido de los acuerdos resultantes de la mediación, a menos que sean contrarios al Derecho del Estado Miembro en el que se haya formulado la demanda o que el Derecho de ese Estado no contemple su ejecutoriedad. Y es en este punto donde surgen las mayores reticencias cuando ante acciones colectivas nos encontramos. Los interrogantes provienen así, fundamentalmente, del carácter ejecutorio de la solución que se alcance, que reviste un cariz especial en los litigios colectivos en los que no todos los miembros del grupo participan de forma directa en la solución consensuada. Por ello, resulta fundamental el papel de control de la legalidad de la solución consensuada que debe realizar el juez. En esta línea, la Comisión Europea ha declarado que la legalidad de toda decisión resultante de una transacción colectiva debe ser controlada por los órganos jurisdiccionales, que velarán por la adecuada protección de los intereses y derechos de todas las partes implicadas (punto 28 de la Recomendación).

Desde las instancias europeas se alienta al establecimiento de sistemas ADR a escala europea y se insta a que los Estados Miembros garanticen que los mecanismos judiciales de las acciones colectivas incluyan la posibilidad de que las partes, antes y durante el litigio, puedan acceder a las modalidades alternativas de solución colectiva de conflictos. Para ello, señala la Comisión en su Recomendación de 20I3, el eventual plazo de prescripción aplicable a las demandas debería suspenderse durante el período comprendido entre el momento en que las partes acuerdan resolver el conflicto por un procedimiento de resolución alternativa de conflictos hasta, como mínimo, el momento en que una o ambas partes se retiren expresamente de dicho procedimiento.

${ }^{45}$ El Parlamento Europeo considera que los criterios elaborados por el Tribunal de Justicia deben constituir el punto de partida para el establecimiento de esta facultad. Vid. Sentencia de I8 de marzo de 20ı, Alassini y otros (C-3I7/08, C-3I8/08, C-3I9/08 y C-320/08), en donde se afirma que el principio de tutela judicial efectiva no se opone a una normativa nacional que impone, para determinados litigios, la tramitación previa de un procedimiento de conciliación extrajudicial cuando dicho procedimiento no conduce a una decisión vinculante para las partes, no implica un retraso sustancial a efectos de la interposición de un recurso judicial, interrumpe la prescripción de los correspondientes derechos y no ocasiona gastos $\mathrm{u}$ ocasiona gastos escasamente significativos para las partes, y siempre y cuando la vía electrónica no constituya el único medio de acceder a ese procedimiento de conciliación y sea posible adoptar medidas provisionales en aquellos supuestos excepcionales en los que la urgencia de la situación lo exija. 
IV.2. Viabilidad o no del ejercicio de acciones colectivas a través de fórmulas transaccionales o del arbitraje.

A la hora de analizar la posible introducción de fórmulas ADR en las acciones colectivas de consumo, conviene distinguir los casos de transacciones (que serán posteriormente homologadas judicialmente), de los de arbitraje, por la dispar solución a la que llegaremos en unos supuestos $u$ otros.

\section{IV.2.I. Las transacciones colectivas}

Algunos Estados de la Unión Europea, principalmente, Holanda, regulan las transacciones colectivas. No es el caso de nuestro país, el cual, si bien no las regula expresamente, debemos añadir, tampoco las prohíbe. No se impide, por tanto, en nuestro ordenamiento procesal, la posibilidad de que se ponga fin a un proceso colectivo por medio de una transacción, siempre y cuando claro está, el derecho o interés en juego sea de carácter disponible ${ }^{46}$. Partiendo de esta premisa, veamos la posible formulación de este tipo de acuerdos cuando ante una pluralidad de derechos o intereses colectivos nos encontremos.

No se admiten en el ordenamiento español, a diferencia de lo que ocurre en otros ordenamientos jurídicos como el holandés, las transacciones extra procesales sobre derechos colectivos. Para que las transacciones produzcan eficacia ultra partes, es decir, para que afecten a aquellas personas pertenecientes al grupo que no han intervenido en el proceso, se debe, sin embargo, incoar un proceso colectivo en el seno del cual se lleve a cabo dicha transacción, que posteriormente deberá ser homologada judicialmente ${ }^{47}$. Para ello, partimos de una aceptación generalizada de que la atribución de legitimación extraordinaria en los procesos colectivos de consumo no sólo abarca el ejercicio ordinario de acciones colectivas, sino también la facultad de negociar actos de disposición sobre el objeto del proceso que puedan alcanzar fuerza vinculante para todos aquellos sujetos cuyos intereses se vean afectados ${ }^{48}$.

En las transacciones colectivas resulta clave que coincida, en la mayor medida de lo posible, el ámbito de la controversia colectiva subyacente con el contenido del acuerdo

\footnotetext{
${ }^{46}$ No vamos a detenernos a analizar la cuestión de la disponibilidad de los derechos o intereses colectivos, pues excedería del objeto de nuestro trabajo, por lo que nos remitimos a la monografía de GASCÓN INCHAUSTI, F., Tutela judicial de los consumidores $y$ transacciones colectivas, cit., en la que se estudia con detenimiento esta cuestión. Como manifiesta este autor, en principio puede predicarse el carácter disponible de la materia, que está regida por el derecho privado, sin perjuicio de que la naturaleza stricto sensu de ciertos bienes, derechos o intereses pueda excluir o limitar en alguna medida su disponibilidad. La regla general de disponibilidad de los derechos de naturaleza privada justifica plenamente plantearse la posibilidad de que existan transacciones en el ámbito de las acciones colectivas.

${ }^{47}$ En sentido contrario, algunas voces, si bien encuentran justificado el efecto vinculante de la decisión judicial en las acciones colectivas respecto de las partes ausentes, consideran que dicho efecto no debe desplegarse en el supuesto en el que se haya solucionado el conflicto por medio de una transacción, pues el mismo no descansa en la potestad judicial, sino en el acuerdo de las partes, respecto del cual las partes ausentes no ha intervenido. Concluyen, así, que su aprobación por parte del juez difícilmente puede salvar el déficit de representación de los ausentes. Cfr. FISS, O. M. y BronsteEn, J., «The class action rule», Notre Dame Law Review, 78-5, 2003 , pág. 1448.

${ }^{48}$ En este sentido, GASCÓn InCHAUSTI, F., Tutela judicial de los consumidores y transacciones colectivas, cit., pág. I87. Manifiesta este autor, que se atribuye legitimación extraordinaria a ciertos sujetos no ya para interponer acciones colectivas, sino en un sentido más amplio, para promover la solución de la controversia en un contexto jurisdiccional, sea a través de una sentencia, sea a través de un acuerdo que resulte satisfactorio y que, en consecuencia, pueda recibir la homologación del tribunal.
} 
adoptado, en aras a garantizar la efectividad de la transacción que ponga fin al conflicto ${ }^{49}$. Únicamente de esta manera, el demandado podrá obtener la certeza de que el acuerdo ha quedado realmente concluido y no existirán eventuales futuros litigios que versen sobre la misma cuestión; de modo que si éstos surgen, se podrá oponer a ellos.

Las reglas generales que deben informar la validez del acuerdo o transacción colectiva, a efectos de su homologación judicial, son: la disponibilidad de la materia, que no sea contraria a las normas imperativas y prohibitivas, que no contraríe la buena fe y que no se adopten en perjuicio de un tercero ${ }^{50}$. No existe en nuestro ordenamiento apenas trámite procesal para que el juez pueda discutir la suficiencia y razonabilidad de los acuerdos transaccionales que los abogados del grupo hayan concluido con el demandado ${ }^{51}$. A pesar de que no se regule expresamente un control del juez del contenido del acuerdo en un proceso colectivo, consideramos que dicho control se convierte en una pieza clave y decisiva, a través de la cual se debe comprobar que efectivamente se están defendiendo los intereses de una colectividad. Lo único que encontramos es el artículo 4I5 LEC, regulador del intento de conciliación o transacción en la audiencia previa al juicio, en donde se manifiesta que el tribunal deberá examinar previamente la concurrencia de los requisitos de capacidad jurídica y poder de disposición de las partes o de sus representantes debidamente acreditados, que asistan al acto; lo que no resulta suficiente, al menos en los procesos colectivos.

En todo caso, consideramos que para proteger los intereses y derechos de quienes no se encuentren presentes en el proceso, deben adoptarse una serie de cautelas. En primer lugar, deben garantizarse mecanismos adecuados de publicidad o comunicación de la interposición de la demanda. Para ello y en la medida de lo posible, se debería proveer de una audiencia en la que se justifique la admisibilidad de lo acordado y se tenga oportunidad de oír a los afectados por el acuerdo y a los terceros que acrediten un interés ${ }^{52}$. Además, tal y como prevé el modelo holandés de transacciones colectivas que vamos a ver a continuación, consideramos acertada la posibilidad de nombrar de oficio a peritos que auxilien al juez en la ardua tarea que puede llegar a suponer valorar y homologar un acuerdo adoptado en una transacción colectiva.

${ }^{49}$ GASCÓn InCHAUSTI, F., Tutela judicial de los consumidores $y$ transacciones colectivas, cit., pág. 33. Como señala este autor, es necesario que el demandado pueda presumir que, celebrada la transacción, no quedan «flecos sueltos» que se conviertan en litigios futuros o que si se dan, pueda evitarlos aduciendo la celebración de la transacción. Además, cuanto mayor sea el ámbito subjetivo de la transacción, mayor será la capacidad negociadora de quien actúe como demandante y mayor será también el interés del demandado en pactar.

5o Armenta Deu, Ma.T., Acciones colectivas: reconocimiento, cosa juzgada y ejecución, Madrid, Marcial Pons, 2013, pág. 36.

${ }^{51}$ En contra de lo que sucede en la Rule 23 USA, no existe en la LEC ningún control judicial al poder de disposición del grupo o asociación sobre el objeto del proceso. CARrasco PererA, A., «¿Acciones de clase en el proceso civil?», Revista doctrinal Aranzadi Civil- Mercantil, 3, 200I, pág. II.

52 Armenta Deu, Ma.T., Acciones colectivas: reconocimiento, cosa juzgada y ejecución, cit., págs. 56 y 57. Compartimos con esta autora que a la audiencia judicial propuesta deberán poder asistir y efectuar alegaciones cualquier entidad legitimada para el ejercicio de la acción. La participación de los consumidores a título individual resulta más cuestionable, ya que si bien podrían intervenir para denunciar eventuales fraudes o conflictos de interés, también serviría que éstos se dirigieran a las entidades legitimadas para que éstas intervinieran. En esta línea, las Federal Rules of Civil Procedure estadounidenses que regulan las class actions, exigen necesariamente en su Regla 23.e.2) la celebración de una audiencia con el fin de determinar si la propuesta de acuerdo es equilibrada, razonable y adecuada. 
Una vez homologado el acuerdo, será equiparado a los títulos judiciales ${ }^{53}$. En nuestro país, el artículo 5I7.2.3. LEC otorga fuerza ejecutiva a las resoluciones judiciales que aprueben $\mathrm{u}$ homologuen transacciones judiciales y acuerdos logrados en el proceso ${ }^{54}$. Asimismo, podrá predicarse de tales resoluciones la misma preclusión que la de las sentencias que ponen fin a un proceso, en el sentido de que ya no podrá interponerse respecto del mismo hecho dañoso otro proceso, ya sea colectivo o individual, a no ser que lo haga aquél que ejercitó en su momento su derecho de exclusión.

Por este motivo, a los consumidores afectados se les deberá otorgar la facultad de excluirse o desvincularse de la transacción. Para ello, tendrá que darse publicidad del acuerdo (antes de su homologación por el tribunal), y un plazo para que aquellos que lo deseen, se desmarquen expresamente del mismo. Tengamos en cuenta que está en juego el Derecho de defensa de una pluralidad de sujetos que pueden llegar a verse afectados por una decisión homologada judicialmente, sin que se les haya oído. Por lo que una de las cuestiones más endebles se centra en la extensión subjetiva de la cosa juzgada respecto de terceros que no han optado expresamente por participar en la transacción. En este sentido, señala GASCÓN INCHAUSTI, que desde una perspectiva jurídica continental lo que más complejo resulta de asumir es que lo acordado por unos pocos tenga efectos vinculantes para un colectivo amplio. De modo que son tres, los elementos clave para que sea legítima esa extensión de eficacia a terceros, propia de un sistema opt-out: que los terceros beneficiarios tengan conocimiento del contenido de lo acordado, que tengan derecho a excluirse del acuerdo y que haya un genuino control judicial del contenido del pacto ${ }^{55}$.

\section{IV.2.2. El arbitraje colectivo}

El arbitraje es una de las fórmulas de resolución de conflictos alternativa a la justicia que mayor éxito ha alcanzo en la práctica. Sin embargo, no se ha utilizado hasta el momento para la tutela colectiva de derechos e intereses en Europa (ni concretamente, en nuestro país), pues encontramos múltiples óbices que dificultan su aplicación en este ámbito ${ }^{56}$.

Nada impide que una entidad ofrezca a un grupo de afectados por un hecho dañoso, o a la asociación que pueda representarlos, someterse a un convenio arbitral único, que permita dilucidar en un solo proceso el conflicto colectivo. Pero en este caso, el laudo que se dicte únicamente vinculará a los concretos intervinientes en el arbitraje, pues no existe en la

${ }_{53}$ Artículo 58 Reglamento Bruselas I: «Las transacciones celebradas ante el tribunal durante un proceso $Y$ ejecutorias en el Estado miembro de origen serán ejecutorias en el Estado miembro requerido, en las mismas condiciones que los documentos públicos con fuerza ejecutiva».

${ }^{54}$ En este mismo sentido, el artículo 4I5 LEC proclama que el acuerdo homologado judicialmente surtirá los efectos atribuidos por la ley a la transacción judicial y podrá llevarse a efecto por los trámites previstos para la ejecución de sentencias y convenios judicialmente aprobados.

${ }^{55}$ Gascón Inchausti, F., Tutela judicial de los consumidores $y$ transacciones colectivas, cit., págs. 78 y 79. Reconoce este autor que no existe sustento legal expreso para algunas de las cuestiones que hemos mencionado, pero que una interpretación más o menos extensiva de algunos preceptos vigentes daría cierta cobertura a un tribunal que quisiera dotar a la aprobación de una transacción de la seriedad que merece. Así, la publicidad del acuerdo y la información de excluirse pueden vincularse al art. I5 LEC; la convocatoria de una audiencia se puede justificar aplicando las normas sobre incidentes de previo pronunciamiento (art. 393.2 y 393.3 LEC); la designación de oficio de un perito puede justificarse por analogía de lo dispuesto en el art. 7I5 LEC para la cuantificación de daños y perjuicios, etc.

${ }^{56} \mathrm{Ni}$ siquiera ninguna institución arbitral europea ha previsto alguna suerte de acción colectiva en sus reglamentos. 
normativa arbitral vigente en la Unión Europea ninguna disposición que permita extender los efectos del laudo a todos los que, aunque no hayan litigado, reúnan las características necesarias para acogerse al ámbito subjetivo de la decisión arbitral57.

A primera vista, parece que las acciones colectivas y la institución del arbitraje se excluyen mutuamente ${ }^{58}$. Los procesos colectivos son complejos, implican numerosas cuestiones jurídicas y pueden llegar a afectar a un número muy elevado de personas, mientras que el arbitraje es un método alternativo de resolución de conflictos caracterizado por la autonomía de la voluntad de las partes y por su flexibilidad e informalidad. La doctrina mayoritaria considera que las ventajas del arbitraje no resultan compatibles con el esquema de las acciones colectivas, por lo que será preferible que la oferta de arbitraje se haga de modo individual a cada afectado, que podrá así obtener una solución individualizada para su caso ${ }^{59}$. Se ha criticado que reconocer la posibilidad de interponer acciones colectivas en el arbitraje, incumpliría los objetivos para los que fue creada esta institución con respeto de sus principios fundamentales de rapidez, antiformalismo y gratuidad (en el caso de consumo) ${ }^{60}$. Son diversos los obstáculos que se erigen y a ellos vamos a dedicar las líneas que prosiguen.

En primer lugar, destacamos la naturaleza voluntaria y consensual que protagoniza esta institución (principal diferencia con la jurisdicción). Únicamente las partes que acuerdan voluntariamente acudir al arbitraje, podrán someterse al mismo. Tal vez sea ésta una de las razones por las que consideramos que en el caso en el que se llegue a aceptar el arbitraje colectivo, la participación en el mismo sea según el modelo opt in. Pues la cosa juzgada podría conllevar el peligro de extenderse a personas que, sin conocimiento previo del litigio y de su resolución por este medio, resultaran afectadas por un laudo, viéndose privadas del acceso a los tribunales jurisdiccionales.

De hecho, la cosa juzgada constituye el mayor obstáculo con el que se encuentran las acciones colectivas en la vía arbitral. Como hemos repetido a lo largo de este trabajo, las resoluciones judiciales que ponen término a los procesos colectivas tienen efecto de cosa juzgada en relación con todos los perjudicados, se hayan personado o no en el procedimiento. Si lo mismo se aplicara a la acción colectiva o difusa planteada en sede arbitral, sucedería que los consumidores que quisieran participar tendrían que hacerlo en

\footnotetext{
${ }^{57}$ Recomendamos la lectura de Billiet, P. (ed.), Class arbitration in the European Union, Antwerpen, Maklu, 20I3. En esta monografía se analiza el régimen jurídico de las acciones colectivas en diferentes países de la Unión Europea (Francia, República Checa, Hungría, Italia, Portugal, etc.) y la posible introducción del arbitraje en esta materia. En todos los capítulos se llega a la conclusión de que, hoy por hoy, en sus respectivas legislaciones no se contempla dicha posibilidad. Sin embargo, la mayoría de autores de este libro consideran factible su viabilidad en un futuro no tan lejano.

${ }^{58}$ En esta línea: Tuchmann, E., «The administration of class action arbitrations», en The Permanent Court of Arbitration (ed.), Multiple Party Actions in International Arbitration, Oxford, Oxford University Press, 2009, pág. 327.

59 Así ha sucedido, precisamente, con los conflictos derivados de la comercialización de instrumentos híbridos por la entidad financiera Novacaixagalicia Banco. La oferta arbitral se planteó a aquellos consumidores o inversores que, por su perfil, reunían las características más adecuadas para acudir al arbitraje y ha permitido que en un breve lapso de tiempo se hayan resuelto miles de reclamaciones. En este sentido, FERREREs ComelLA, A. y LóPEZ DE ARGUMedo, A., «Las limitaciones del sistema de tutela colectiva de intereses individuales homogéneos dispuesto en nuestra Ley de Enjuiciamiento Civil. Una propuesta inicial de sistemas alternativos de resolución de conflictos» (disponible en:

http://www.uria.com/documentos/publicaciones/3609/documento/ari.pdf?id=44I6).

${ }^{60}$ Casado Cerviño, A., «El arbitraje de consumo», Actualidad Civil, 4, 2006, pág. I4.
} 
ese procedimiento arbitral ya iniciado, sin tener opción alguna de acudir a la vía jurisdiccional, lo que supondría una vulneración del derecho constitucional a la tutela judicial efectiva. Por tanto, pensamos que si se admitiera a día de hoy la posibilidad de interponer acciones colectivas en el arbitraje, se tendría que respetar en todo caso, que el consumidor individual pudiera acudir a la vía jurisdiccional para defender sus intereses ${ }^{61}$.

En este sentido, autores como MARCOS FRANCISCO han señalado que el convenio y el laudo arbitral o, en definitiva, el arbitraje como institución esencialmente voluntaria, sólo tiene efectos inter partes, no pudiendo tener efectos erga omnes ${ }^{62}$, lo que es incompatible con el régimen procesal singular de las acciones colectivas, en aspectos tales como la eficacia de cosa juzgada de la que gozan las sentencias que las resuelven en relación con todos los perjudicados, se hayan personado o no en el procedimiento, siempre que hayan tenido oportunidad de participar en él. De modo que, si aplicáramos tal régimen en sede de arbitraje de consumo estaríamos atentando contra el derecho fundamental a la tutela judicial efectiva reconocido en el artículo 24.I de la Constitución Española, ya que no cabría otra opción para los consumidores perjudicados del colectivo que acudir a esta vía (y no a la judicial) una vez iniciado el procedimiento arbitral ${ }^{63}$.

Además, también podrían surgir problemas de reconocimiento y ejecución del laudo dictado en un proceso colectivo en el extranjero, especialmente en aquellos países que han optado por un sistema de opt out. En este sentido, el Convenio sobre reconocimiento y ejecución de sentencias arbitrales extranjeras de I958, en su artículo V.r.b, manifiesta que se podrá denegar el reconocimiento y la ejecución del laudo a instancia de la parte contra la cual es invocada, si esta parte prueba ante la autoridad competente del país en que se pide el reconocimiento y la ejecución: "Que la parte contra la cual se invoca la sentencia arbitral no ha sido debidamente notificada de la designación del árbitro o del procedimiento de arbitraje o no ha podido, por cualquier otra razón, hacer valer sus medios de defensa». Por lo tanto, cualquier integrante del grupo que no fue avisado ni notificado de la acción colectiva arbitral, podrá tratar de oponerse al reconocimiento del laudo.

Otro aspecto a tener en cuenta es el de la confidencialidad, uno de los rasgos más característicos del arbitraje y una de las principales razones por las cuales se acude a este medio de resolución de controversias. Nos preguntamos cómo, en el supuesto de un arbitraje colectivo, puede darse publicidad para atraer a las partes perjudicadas al mismo sin contravenir la confidencialidad propia de esta institución. Se trata de una cuestión compleja, de difícil solución, especialmente en los sistemas de opt- out. Tememos que para

\footnotetext{
${ }^{61}$ MARín LóPEZ, M.J., «Objeto y límites del arbitraje de consumo», Revista Jurídica de Castilla La Mancha, 39, 2005, pág. I83. Este autor recuerda la Sentencia de la Audiencia Provincial de Barcelona, de 3 de noviembre de 2003 (AC 2003, I763), en donde se entiende que una acción colectiva no puede someterse a la decisión de los árbitros por tratarse de una materia que no es de libre disposición para un consumidor, pues el demandante en un arbitraje no puede disponer de derechos colectivos que pertenecen o afectan a un número indeterminado de personas.

${ }^{62}$ El arbitraje sólo puede afectar a quienes a él se sometieron (STS de 28 de mayo de I990, RJ I990, 4048) y la cláusula de sumisión a arbitraje no puede afectar a terceros ajenos a la celebración del contrato, para quienes dicha cláusula es «res inter alios acta», (SAP de Valencia de I9 de noviembre de 200I, JUR 2002, 4235I).

${ }_{63}$ Marcos Francisco, D., «¿Es posible la tutela de intereses colectivos y difusos en el arbitraje de consumo?», Iuris Tantum Revista Boliviana de Derecho, II, enero 20II, págs. I84 y I85.
} 
lograr la efectividad de un arbitraje colectivo, probablemente ésta sería una de las características del arbitraje que tendría que ceder y verse mermada ${ }^{64}$.

Son otros muchos los interrogantes que plantea la interposición de acciones colectivas en el arbitraje. Entre otros, la arbitrabilidad de la controversia; el respeto del debido proceso, la posibilidad de ejecutar en nuestro país un laudo colectivo dictado en otro país, etc. Cuestiones que no entramos a debatir por exceder del objeto de este trabajo, pero que no por ello carecen de interés.

A pesar de tales obstáculos, pensamos que el arbitraje puede proporcionar a los procesos colectivos algunas ventajas. Muestra de ello, puede observarse en el ordenamiento jurídico estadounidense, que nos ha mostrado la viabilidad de su práctica ${ }^{65}$. Entre otras, la especialidad de los árbitros ayudará a resolver con eficacia y mayor premura las difíciles cuestiones jurídicas que estos procesos pueden llegar a plantear. Asimismo, se podrán solventar muchos de los problemas que se plantean a la hora de determinar el tribunal competente cuando ante un litigio internacional nos encontremos, pues serán las partes las que podrán escoger el mismo de acuerdo a sus necesidades. Y todo ello, sin hacer mención a la propia naturaleza de la institución arbitral que lleva inherente, en la mayoría de ocasiones, el deseo de las partes de alcanzar un acuerdo.

A la vista del éxito que han ido adquiriendo en los últimos años las acciones colectivas junto con la arraigada tradición de las fórmulas ADR en Europa, -no por ello dejando de ser conscientes de las trabas con las que contamos en la actualidad-, consideramos que la posibilidad de arbitrar acciones colectivas es una cuestión de tiempo ${ }^{66}$. Además, pensamos que dicha opción vendrá de la mano del desarrollo de fórmulas alternativas que se lleven a cabo on-line (los conocidos por todos, Online Dispute Resolution, ODR) ${ }^{67}$.

En nuestro país, se ha previsto en el RD 231/2008 regulador del sistema arbitral de consumo lo que se denomina «arbitraje colectivo de consumo», al cual vamos a dedicar el

${ }^{64}$ A título de ejemplo, la American Arbitration Association (AAA), al aceptar la «class action arbitration», dejó de proteger la confidencialidad de los procedimientos arbitrales colectivos. Prueba de ello es que casi todos los laudos en estos procesos se encuentran disponibles en su web.

${ }^{65}$ Los arbitrajes colectivos (class arbitration) existen en Estados Unidos desde hace más de 25 años. A pesar de no contar con una legislación propia, han ido adoptando forma y extendiéndose en la práctica, especialmente, cuando instituciones arbitrales tales como la American Arbitration Association y la Judicial Arbitration and Mediation Services (JAMS), decidieron aprobar regulaciones específicas para este tipo de arbitraje. Para hacernos una idea, la AAA desde 2007 ya ha administrado más de I20 class arbitrations. BILLIET, P., «Introduction», en ID. (ed.), Class arbitration in the European Union..., cit., pág. I2. Vid. asimismo, NATER-BAss, G ., «Class action arbitration: a new challenge?», en MÜLLER, C. y RIGOZZI, A. (ed.), New developments in international commercial arbitration, Zurich, Schulthess, 2008, págs. 27-59; y HANOTIAU, B., Complex Arbitrations (Multiparty, Multicontract, Multi-issue and Class Actions), Países Bajos, Kluwer International, 2005, págs. 267-279.

${ }^{66}$ Pensemos, por ejemplo, que durante muchos años diversos países de la Unión Europea han permanecido escépticos frente a las acciones de clase estadounidenses. Finalmente, el incremento de la contratación masiva en las últimas décadas ha invitado a estos países a reconsiderar su resistencia frente a esta herramienta. Por otro lado, el éxito del arbitraje ha ido asentándose. De modo que es más que probable que estas dos instituciones se unan, aunque todavía quede algún tiempo.

${ }^{67}$ El medio «on-line» puede convertirse en un foro muy óptimo para la resolución de disputas masivas con afectados que se encuentran en distintos países de Europa, lo que cada vez es más común como consecuencia del incremento de transacciones comerciales de consumo vía Internet. Para ello, las redes europeas existentes, como la Red CEC o FIN-Net, que ya ayudan a los consumidores de forma individual a acceder a los mecanismos de solución alternativa de conflictos en otro país, también podrían ayudar a los consumidores con denuncias similares a acceder a los mecanismos adecuados de solución alternativa de conflictos colectiva en otro Estado miembro. 
epígrafe posterior. A pesar de su denominación, no cabe ejercitar a través del mismo ni la acción de cesación, ni las acciones por intereses colectivos o difusos a los que se refiere el artículo II LEC. El sistema arbitral de consumo español permite conocer las reclamaciones individuales o incluso colectivas de consumidores pero siempre que los mismos se personen en el procedimiento arbitral. De modo que el laudo únicamente afectará a los consumidores personados. En definitiva, por mucho que la nueva regulación el sistema arbitral de consumo haya regulado una suerte de arbitraje colectivo, - que propiamente no es tal -, el ejercicio de intereses colectivos y difusos solo pueden ejercitarse por vía jurisdiccional.

\section{IV.3. Experiencias europeas}

Vamos a exponer en este apartado en primer lugar, el ya mencionado arbitraje colectivo de consumo español y a continuación, dedicaremos el resto de líneas al ejemplo europeo pionero en la materia que estamos estudiando, es decir, a las transacciones colectivas en materia de daños en masa reguladas en el ordenamiento holandés.

IV.3.I. El arbitraje colectivo de consumo español

El Real Decreto 23I/2008, de I5 de febrero por el que se regula el Sistema Arbitral de Consumo (en adelante, RD) introdujo como novedad en el ordenamiento español, la regulación del arbitraje de consumo colectivo, en sus artículos 56 a 62 .

El artículo 56 del Real Decreto define el arbitraje colectivo de consumo como aquél que «tiene por objeto resolver en un único procedimiento arbitral de consumo los conflictos que, en base al mismo presupuesto fáctico, hayan podido lesionar los intereses colectivos de los consumidores $y$ usuarios, afectando a un número determinado o determinable de éstos». Se regula, por tanto, el arbitraje de consumo como vía de tutela de los intereses colectivos en los que los sujetos perjudicados por el hecho dañoso son un grupo de consumidores determinado o de fácil determinación. No cabe, sin embargo, el arbitraje de consumo para tutelar los intereses difusos. E incluso cuando tutele los intereses colectivos, únicamente afectará a aquellos consumidores que se personan en el procedimiento arbitral.

Tal y como señala el artículo 57 RD, será la Junta Arbitral de Consumo competente en todo el ámbito territorial en el que estén domiciliados los consumidores y usuarios, cuyos legítimos derechos e intereses económicos hayan podido verse afectados por el hecho, quien conozca de los procedimientos arbitrales colectivos ${ }^{68}$. Por su parte, cuando los consumidores y usuarios afectados se encuentren domiciliados en más de una Comunidad Autónoma, corresponderá a la Junta Arbitral Nacional conocer del procedimiento arbitral colectivo. En ningún caso las partes podrán pactar la junta competente que deseen arbitre su controversia.

\footnotetext{
${ }^{68}$ MARCOS FRANCISCO subraya que este precepto parece ignorar que en un principio puedan desconocerse todos los consumidores cuyos intereses han sido afectados. Además, tampoco nos ofrece unas pautas acerca de cómo se debe proceder en aquellos casos en los que en un inicio figuran como afectados consumidores de una misma zona sobre la que tiene competencia una Junta Arbitral de consumo y, posteriormente, sea durante la fase de llamamiento o ya iniciado el procedimiento arbitral pero antes de la audiencia, aparecen y presentan su solicitud de arbitraje para intervenir en el mismo procedimiento consumidores domiciliados en zonas sobre las que es competente otra Junta Arbitral; vid. MARCos Francisco, D., «¿Es posible la tutela de intereses colectivos y difusos en el arbitraje de consumo?», cit., pág. I9I.
} 
En este tipo de arbitraje únicamente existe legitimación directa, no cabe por tanto, la legitimación indirecta representativa que se emplea para el ejercicio de los «intereses colectivos o difusos» del artículo in LEC. El procedimiento arbitral colectivo básicamente consiste en lo siguiente. El presidente de la Junta Arbitral competente adoptará un acuerdo de iniciación de las actuaciones, lo que podrá hacer de oficio o a iniciativa de las asociaciones de consumidores representativas en ese territorio o de las Juntas Arbitrales de inferior ámbito territorial. Adoptado el mismo, la Junta requerirá a la empresa o profesional responsable de los hechos para que manifieste, en el plazo de quince días, si acepta someterse al arbitraje de consumo colectivo y, en su caso, para que proponga un acuerdo conciliatorio que satisfaga total o parcialmente a los potenciales consumidores afectados ${ }^{69}$.

Si la empresa no acepta, se archivarán las actuaciones (art. 58 RD). Si por el contrario manifiesta su deseo de someterse al arbitraje, se procederá al llamamiento de todos los consumidores afectados para que se personen y hagan valer sus derechos mediante la publicación de un anuncio en el Diario Oficial del ámbito territorial que corresponda (art. 59 RD). El llamamiento se realizará por un plazo de dos meses desde su publicación, transcurrido el cual, el presidente designará al órgano arbitral. Dentro de ese plazo los consumidores que pretendan resolver en ese procedimiento colectivo su conflicto deberán presentar su solicitud. Pasado dicho plazo, sólo se admitirán las solicitudes que se insten antes de la audiencia y sin retrotraer las actuaciones.

La aceptación por parte de la empresa del arbitraje colectivo suspende la tramitación de las solicitudes individuales de arbitraje. Además, también se regula la posibilidad de que el reclamado, en cualquier momento del procedimiento, oponga la excepción de estar tramitándose un arbitraje colectivo, para que se inhiban de su conocimiento y se trasladen las actuaciones a la Junta Arbitral de consumo competente para conocerlo.

Para finalizar, el laudo debe dictarse en un plazo de seis meses que comienza a computar transcurridos dos meses desde la publicación del llamamiento a los afectados en el Diario Oficial (art. 62 RD). Como hemos podido observar, el laudo únicamente afectará a los consumidores que participaron en el procedimiento arbitral, ya sea porque presentaron su solicitud de arbitraje tras el llamamiento, o bien porque su solicitud se estaba tramitando de forma separada y fue traída al arbitraje colectivo. De ese laudo, por tanto, no podrán beneficiarse otros consumidores afectados por esos mismos hechos, pues el laudo no constituye para ellos cosa juzgada, por lo que podrán iniciar los procedimientos judiciales o arbitrales que correspondan.

En definitiva, el arbitraje de consumo colectivo español es un mero mecanismo para resolver en un mismo procedimiento arbitral, las reclamaciones individuales de varios consumidores. No se tutelan ni los daños colectivos de los consumidores, ni los daños individualmente sufridos por los miembros de una colectividad de consumidores. Únicamente el consumidor que se persone en el arbitraje podrá ver resarcido su interés si el laudo es favorable ${ }^{70}$. Por lo que concluimos que no se trata de un proceso colectivo en los

\footnotetext{
${ }^{69} \mathrm{El}$ arbitraje colectivo puede sustanciarse también frente a varios empresarios o profesionales, tal y como se deduce del tenor literal de los preceptos reguladores del mismo.

${ }^{70}$ MARín López, M.J., «La nueva regulación del arbitraje de consumo: el Real Decreto 23I/2008, de I5 de febrero», Diario La Ley, 6905, Sección Doctrina, I7 Mar. 2008, Año XXIX, Ref. D-82, pág.I9.
} 
términos empleados en la vía judicial sino más bien una suerte de acumulación subjetiva de acciones contra un mismo empresario por una similar causa petendi $i^{\text {r }}$.

IV.3.2. La transacción colectiva holandesa en materia de daños en masa

En los Países Bajos existe la llamada Ley sobre Transacciones Colectivas en materia de daños en masa (Wet collectieve afwikkeling massaschade- WCAM) de 2005. Esta ley regula la posibilidad de celebrar transacciones colectivas para obtener indemnizaciones pecuniarias respecto de daños masivos ${ }^{72}$. Por su parte, el código civil y el código procesal holandés regulan el contenido, efectos, impugnación y procedimiento de estas transacciones colectivas ${ }^{73}$.

Están legitimados para negociar y, en su caso, alcanzar una transacción, el responsable del daño y la entidad representativa de los derechos o intereses lesionados (generalmente una fundación o asociación); se impide, por tanto, la negociación a mano de sujetos particulares. Se trata en todo caso de una negociación extraprocesal, pero que requiere del control y aprobación judicial del acuerdo que se adopte para que adquiera fuerza vinculante. El Tribunal competente para tal función será el Tribunal de Apelación de Ámsterdam.

A la hora de llevar a cabo la aprobación del acuerdo, el Tribunal debe ejecutar un doble examen. Por un lado, ha de comprobar si la entidad tiene representatividad suficiente para actuar en nombre de todos los afectados. Por otro, debe llevar a cabo un análisis de razonabilidad en el que debe verificar la corrección del criterio por el que se ha definido el grupo de interesados así como acreditar si la indemnización concedida en la transacción es razonable. Solo si ambos parámetros reciben el visto bueno, se procederá a la aprobación judicial de la transacción ${ }^{74}$.

El procedimiento de homologación de la transacción fundamentalmente consiste en lo siguiente. Alcanzado el acuerdo (fuera de los tribunales), las partes conjuntamente deben solicitar al Tribunal de Apelación de Ámsterdam que declare vinculante el acuerdo. Ante dicha petición, el Tribunal dará la máxima difusión posible de la transacción, informando sobre el contenido del pacto, posibles efectos así como acerca de la celebración de una próxima audiencia en la que se compruebe si su contenido es pertinente. Los sujetos interesados podrán, a partir de entonces, formular por escrito las alegaciones oportunas,

\footnotetext{
${ }^{7 \pi}$ Como señala Cubillo López, por este cauce no se ventila una genuina pretensión de tutela colectiva, en el sentido de que un solo sujeto actúe y defienda en el procedimiento los derechos e intereses de varios, sino que el arbitraje de consumo colectivo supone más bien el ejercicio plural de varias pretensiones que se acumulan en un solo procedimiento; vid. CuBILlo LóPEZ, I.J. (coord.), Cuestiones actuales sobre la protección de los consumidores: tutela penal, civil y arbitral, Navarra, Thomson Reuters-Civitas, 20ı0, pág. 344. Curiosamente, en el Borrador del RD sí que se pretendió introducir el posible ejercicio de acciones colectivas y difusas a través del arbitraje de consumo. Su artículo 5.I, decía así: «La Junta Arbitral Nacional, adscrita al Instituto Nacional de Consumo, será competente para conocer en las reclamaciones surgidas como consecuencia de conflictos surgidos con empresas que lesionen los derechos e intereses colectivos o difusos de los consumidores o usuarios, que residan en más de una Comunidad Autónoma...)».

${ }^{72}$ Llama la atención, sin embargo, que no se permita la acción colectiva por vía judicial sobre esta misma materia.

${ }^{73}$ Vid. VAN DER HeIdjen M.J., «Class Actions/les actions collectives», Electronic Journal of Comparative Law, I4-3, 2010 (disponible en http://www.ejcl.org/I43/arti43-I8.pdf).

${ }^{74}$ Ferreres Comella, A. y López de Argumedo, A., «Las limitaciones del sistema de tutela colectiva de intereses individuales homogéneos dispuesto en nuestra Ley de Enjuiciamiento Civil. Una propuesta inicial de sistemas», Actualidad jurídica Uría Menéndez, nº. extra I, 20I2, pág. II6.
} 
mientras el Tribunal por su parte, podrá solicitar el auxilio de uno o varios peritos para poder realizar un contundente análisis de fondo de la cuestión.

Recibidas las alegaciones e informes periciales, se procederá a celebrar la audiencia, a la que acudirán las partes y en la que se comprobará si se cumplen los requisitos y presupuestos oportunos. Si así lo considera, el Tribunal dictará una resolución por la que se atribuirá fuerza vinculante al acuerdo adoptado por las partes. Esta resolución será publicada para su conocimiento por los sujetos beneficiarios del acuerdo, a los que se les indicará que pueden solicitar su exclusión del mismo si lo desean, durante un determinado plazo que no será inferior a tres meses. Transcurrido el mismo, el acuerdo adquirirá fuerza vinculante frente al resto de sujetos que no se excluyeron (por tanto, ya no podrán acudir a los tribunales para resolver dicha cuestión) y se procederá a su ejecución en los términos que se pactaron.

Si bien Holanda es el país de la Unión Europea que regula de una manera más amplia y completa la transacción en materia de acción colectiva, nos encontramos con otros países que, aunque de una manera más escueta, sus legislaciones también contemplan algún tipo de transacción en los procesos colectivos. Así ocurre, entre otros, en Portugal75, Italia $^{76}$, Dinamarca, y Suecia ${ }^{77}$. Fuera de la Unión Europea, el ejemplo más paradigmático que podemos encontrar de transacciones colectivas es el modelo estadounidense de «class actions» o mejor dicho, «class settlement», en donde un número muy elevado de procesos colectivos finalizan con un acuerdo ${ }^{78}$. Tampoco podemos olvidar mencionar, el Código de Procesos Colectivos para Iberoamérica aprobado por el Instituto Iberoamericano de Derecho Procesal en el año 2004, que contempla asimismo la posible finalización del proceso mediante un acuerdo transaccional ${ }^{79}$.

En suma, consideramos que la situación actual todavía no permite hablar con firmeza y carácter general de las transacciones colectivas y menos aún del arbitraje colectivo, se ha avanzado mucho respecto de hace una década pero el camino es largo y queda un recorrido que debe superar no pocos obstáculos. A pesar de ello, nuestras

${ }^{75}$ El mecanismo portugués más parecido a la acción colectiva es la denominada «acción popular» (acçao popular) regulada en la Ley 83/95. En los procesos en los que se ejercitan estas acciones puede plantearse una transacción o acuerdo entre las partes, pero que deberá ser aprobado por el Tribunal. Además, el Ministerio Fiscal también podrá controlar el contenido de estas transacciones colectivas. Respecto al ordenamiento portugués, recomendamos la lectura de PinTo Monteiro, A. y MiguEL Judice, J., «Class actions \& Arbitration in the European Union- Portugal», en AA.VV, Estudos em Homenagem a Miguel Galvão Teles, volumen II, Coimbra, Almedina, 20I2, págs. I89-205. En él se analiza la posibilidad del arbitraje colectivo en este país. Los autores, conocedores de las ventajas de este tipo de arbitraje, no son sin embargo muy optimistas a la hora de considerar su viabilidad en el momento actual, pero auguran que en un futuro la situación podrá cambiar.

${ }^{76}$ El ordenamiento italiano contempla un mecanismo especial que permite la transacción -homologada por el juez- en las acciones de cesación e inhibición de consumidores. Vid. art. I40 bis del Código de Consumo italiano. GiussanI, A., «L'azione collettiva risarcitoria nell'art. I40 bis c. cons.», Rivista Diritto Processuale, LXIII, 5, 2008 , págs. 1227 y ss.

${ }^{77}$ Gascón Inchausti, F., Tutela judicial de los consumidores $y$ transacciones colectivas, cit., págs. 79-89 y a CARballo PiÑeiro, L., Las acciones colectivas y su eficacia extraterritorial, cit., págs. 220-222.

${ }^{78}$ Vid. López SÁnchez, J., El sistema de las class actions en los Estados Unidos de América, Granada, Comares, 20II. Esta monografía dedica su capítulo octavo al acuerdo -settlement- como forma habitual de terminación del proceso de class actions.

79 Vid. Pereira CAmpo, S., «Los recaudos para aprobar un acuerdo, la cosa juzgada y la liquidación y ejecución de sentencia en los procesos colectivos/class actions en América», Revista Uruguaya de Derecho Procesal, 2, 20II, págs. 897-930. 
expectativas se mantienen favorables a la posible introducción de acciones colectivas de consumo a través de fórmulas alternativas. 